Essa forma de diagnosticar o urbano tem estreitado a capacidade analítica sobre sua dinâmica. Tem permitido projeções ("ao ano 2000") superficiais de nossas cidades, em que pese d̀ sofisticação econométrica e sociomé-

1. Introdução;

2. Questões para um novo planejamento urbano; 3. Questões para um novo diagnóstico, 4. Principais determinantes da dinâmica urbana no estado de São Paulo.

\section{Dinâmica da economia urbana de São Paulo: uma proposta de investigação*}

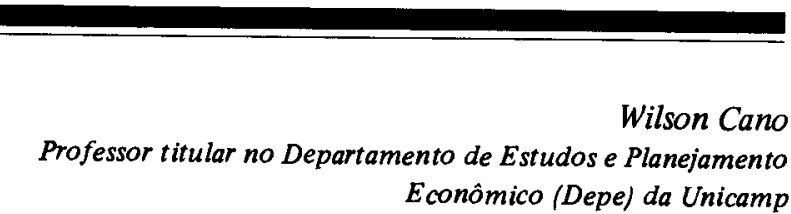

Econômico (Depe) da Unicamp

\section{INTRODUÇÃO}

Nosso objetivo é discutir a urgente reformulação do diagnóstico e do planejamento urbano. Pretendemos criticar a visão tradicional "intramuros" que tem predominado sobre o espaço urbano brasileiro. A dinâmica da economia urbana tem sido estudada de maneira especifica, quando, a nosso juízo, deveria ser pensada num plano global e integrado da economia.

Interessa-nos discutir a alternativa metodológica para estudar e planejar o urbano, não em seus específicos limites e sim como produto de uma dinâmica sócio-econômica, que transcende os limites do urbano. Assim, devemos contemplar, além das variáveis que atuem dentro de um contexto urbano específico, outras que, embora pertençam a outra esfera - a rural - e/ou a ou tros espaços urbanos, têm crucial importância sobre uma específica dinâmica urbana. $O$ espaço aqui enfocado será o do estado de São Paulo.

Diferente desta proposta, a visão "intramuros" estuda o urbano praticamente dentro de seus específicos limites. Não analisa o papel exercido sobre o urbano, pela agricultura paulista. Não cogita também do papel das dinâmicas regionais do Brasil sobre a expansão da massa urbana paulista. Quando muito, considera apenas alguns de seus efeitos aparentes. trica crescentemente adotada. Refeito o diagnóstico, essa visão também deverá ser superada na fase do planejamento, o que ensejará novo detalhamento das principais variáveis responsáveis pela renda e pelo emprego urbanos.

O item 2 ("Questões para um novo planejamento urbano") critica o objetivo explicitado nas políticas de interiorização e de descentralização industrial, propondo readequação da metrópole e uma política de localização regional de atividades econômicas. Tais quiestões estarão articuladas com a do estreitamento atual das finanças públicas estaduais e municipais.

O item 3 ("Questões para um novo diagnóstico") procura se concentrar na revisão da periodização e do espaço. A complexidade da periodização aumenta, dada nossa intenção de nos afastarmos daquela visão que se encerra "intramuros". Ao procurarmos investigar a in. fluência de outros espaços sobre a dinâmica do setor urbano, defrontamo-nos com variáveis de distintas periodizações. Quanto ao âmbito espacial do diagnóstico, os cortes analíticos levarão em conta o município de São Paulo, a aglomeração metropolitana e as principais regiões do estado.

No item 4 , especificaremos os principais determinantes da dinâmica urbana. Consideraremos, primeiro, os determinantes externos ao estado de São Paulo, que atuam na dinâmica urbana deste Estado. Em seguida, especificaremos os principais determinantes internos ao estado de São Paulo, sobre os quais a análise setorial ganhará destaque. Há que evidenciar o impacto que as dinâmicas agrícola e industrial exercem sobre a do setor terciário, além da dinâmica interna própria e restante do urbano, stricto sensu. As açðes da política econômica atuantes sobre a dinâmica urbana também serão contempladas.

\section{QUESTÕES PARA UM NOVO PLANEJAMENTO URBANO}

A população paulista cresceu, ao longo do período de 1940-80, de 7,1 para 25 milhões de habitantes, isto é, 3,5 vezes, ao passo que sua população urbana, no mesmo período, passou de 3,2 milhões para 22,5 milhões de habitantes, isto é, cresceu sete vezes, mostrando o "caráter explosivo" dessa expansão. A taxa de urbanização do Estado é cerca de $88 \%$ e a da Grande São Paulo próxima dos $96 \%$, aí se concentrando a maior parte da população urbana estadual.

$O$ vaticínio e o temor de uma "explosão demográfica", vis-à-vis o agravamento das finanças públicas, estimularam, salvo raras exceçðes, formas de pensar "soluções" escamoteadoras do problema urbano. Isso foi reforçado pelo autoritarismo pós-1964 e as falsas soluçðes traduzem-se em posturas político-institucionais como as de que: "São Paulo precisa parar"; "faz-se necessária uma política de interiorização da indústria"; 
"faz-se necessária uma política de desconcentração in. dustrial" e outras.

Em face desses simplismos, pergunta-se: quais as questðes centrais que nortearam as diversas "polfticas" setoriais e regionais? Como foram consideradas as questőes técnicas e polítícas? Quais se sobrepð̄em prioritariamente a outras? $O$ tema apresenta questðes extremamente complexas que não podem ser respondidas de forma superficial.

Neste trabalho, pretendemos chamar a atenção para alguns equívocos, pois a leitura critica daquelas medidas e do seu discurso político permite-nos concluir que as orientações para tais políticas de interiorização "privilegiaram" a questæo espacial, em detrimento da social. Essa postura tecnocrática produziu, ao longo das últimas duas décadas, um grande acervo de planos, programas e projetos de discutível aplicabilidade concreta, reduzida eficácia e alta dose de distanciamento para com os problemas mais graves que afetam a parte maior da sociedade brasileira, notadamente a de baixa renda.

A título de ilustração, merece destaque a intenção do Governo federal em obrigar, indistintamente, os municípios brasileiros a adotarem o conhecido "Plano Diretor de Desenvolvimento Integrado (PDDI)", que nada mais é do que uma forma de ampliar a demanda de serviços tecnocráticos bem remunerados. Argumentava-se que os municípios com PDDl's aprovados encontrariam maiores exequibilidades para obter recursos financeiros na esfera federal. No entanto, ao se adotar tal medida, estava-se usurpando recursos da própria esfera municipal, em face dos elevados custos para a elaboraçđo desse plano.

0 exposto tem a finalidade de contrapor as questðes técnicas as de ordem política. As orientaçð̃es tecnocrátias padeceram sempre do mesmo vício, isto é, foram implantadas nos marcos do modelo centralizador e autoritário, que ainda permanece na estrutura político-administrativa federal. Essa postura esteve duplamente viciada na sua origem: porque o regime autoritário promoveu uma produção tecnocrática, e porque se valeu de interpretação insuficiente e pouco crítica do fenômeno da urbanização.

Para explicitar melhor nossa crítica, lembramos a política de interiorização que norteou os governos paulistas durante a década de 1970 . Uma leitura atenta deixa clara a quase ausência de consideraçôes sobre a dinâmica da urbanização e sobre as especificidades maiores da estrutura produtiva da economia paulista; da interação de sua agricultura - que passou por profundas transformaçðes - com o próprio setor industrial; a questão da adequação ou não da oferta e demanda de serviços urbanos nas diversas regioes do estado etc.

Entendemos que a interiorização do desenvolvimento deva ser estudada como um processo mais geral, pelo qual passa a economia capitalista, que envolve tanto questðes migratórias e as atinentes à intensificação capitalista da produção no campo, quanto as da própria dinâmica da expansđ̃o de diferenciação dos serviços nos grandes centros urbanos.

Assim, há que se entender criticamente o sentido da política de descentralização industrial (ou a de interiorização), sem o que persistirá o risco das falsas soluçőes. $\mathbf{E}$ preciso repensar as políticas concebidas para as áreas metropolitanas e sua possível readequação. Além disso, faz-se necessário o desenho de uma efetiva política de localização industrial e ó reestudo da dinâmica do fenômeno da urbanização, substituindo-se sua visão "intramuros". Estas sugestōes serão aprofundadas no item 4 deste texto.

Isso posto, cabe responder de forma mais detalhada a seguinte questão: por que, nas circunstâncias politicas e econômicas atuais, as políticas de interiorização do desenvolvimento $\mathrm{e} / \mathrm{ou}$ da descentralização industrial sto escamoteadoras?

O escamoteamento reside no fato de que se tenta interiorizar e/ou "descentralizar" indústrias, atividades de ordem econômica de modo geral e, até mesmo, orgãos estaduais, como foi a proposta da "Nova Capital", durante o governo Maluf, a pre texto de "harmonizar a expansão urbana em face do chamado caos urbano". Ou seja: a pretexto de desenvolver o interior (do país ou de um estado), tenta-se, na verdade, transferir espacialmente alguns problemas de complexa solução. Por exemplo, transferir determinada indústria poluidora porque o custo político e econômico da despoluição é alto.

Lembremos que o desenvolvimento econômico do país, nos últimos 50 anos, não se resume à considerável expansão industrial, com seus enormes efeitos de urbanização. Isto foi acompanhado por uma expansão capitalista diversificada na agricultura, que também repercute no urbano, não só com efeitos positivos, mas também com os efeitos negativos do êxodo rural. Além disso, não se pode ignorar a considerável expansão havida com o terciário e a construção civil.

A escamoteação também decorre de que, ao não se estudar profundamente a dinâmica do urbano, é incorreto tentar-se descentralizar a economia urbana, valendo-se de precários estudos de processos insuficientemente interpretados. Ainda é incipiente o conhecimento dos custos derivados da descentralização e/ou interio. rização, como também pouco se sabe sobre a interação da agricultura com a indústria e destas com a dinâmica das cidades. Não e demais lembrar que existem inđústrias que apresentam intricados problemas técnicos e econômicos de descentralização espacial.

O autoritarismo tecnocrático e a ausência de um correto diagnóstico tomaram o poder público estadual e municipal impotente financeira, politica e tecnicamente diante dessa incontida expansão urbana. $O$ resultado não se fez esperar: os estados adotaram rapidamente a fórmula simplista da "descentralização", e os municípios a ilusão das políticas de atração das indústrias.

Diante desse quadro confuso há que se pensar em readequaçðes das regiðes metropolitanas, ao mesmo tempo em que se prepara e se adequa novas áreas de menor dimensão (em outras cidades), a fim de se antecipar ao agravamento de problemas que persistirão nas grandes áreas metropolitanas e que vêm gerando a degradação de cidades de porte médio.

Para que essa proposição possa ser mais bem estudada, deve se ter claro que está inserida dentro de uma nova postura política e que passa, necessariamente, pelas questőes da participação das finanças públicas e da construção das linhas gerais de uma efetiva e dinâmica política de localização de atividades econômicas. 
Com relação às readequaçðes das regiøes metropolitanas, há que se ver com outros olhos a questão da finança e do gasto público e se fazer um planejamento urbano que dê conta dos reais interesses da coletividade e não daqueles decorrentes dos determinantes dos lucros imobiliários que, em grande parte, estimulam uma verdadeira ciranda de especulaçáo imobiliária.

Algumas administrações de cidades de porte médio do interior de São Paulo adotaram postura mais crítica frente a essas questðes, viabilizando, com seus próprios recursos, melhores soluções para alguns problemas urbanos.

Contudo, tem predominado a postura tradicional. Por exemplo, a localização de conjuntos habitacionais tem significado, predominantemente, a "urbanização" de espaços vazios destinados à especulação. Conseqüentemente, os problemas daf advindos (transportes coletivos, saneamento básico, ihuminação publica etc.) passam a onerar em demasia os gastos públicos. Por isso, faz-se necessário, também, repensar a alternativa do crescimento horizontal ou vertical das cidades.

E oportuno lembrar a necessidade urgente de se efetivar a participação democrática do povo na tomada das decisōes. Embora essa constituísse uma das principais promessas explícitas dos candidatos de oposição nas eleições de 1982, foi escassamente posta em prática.

Recentes e elevados aumentos na carga tributária estadual e de inumeros munić́pios, sem ampla discussão e consulta, atestam sua ausência. A continuidade da "privatização" do setor público corrobora o fato. Diante da autoritária e consumada estrutura tributária nacional, as prefeituras municipais - de oposição ou não - com raras excę̧ðes, acostumaram-se a isso, continuando a exercer em estilo privado - com objetivo de lucro - gastos que são essencialmente públicos. Esta maneira de operar a coisa pública somente podera ser alterada mediante decisiva participação popular.

A questão da localização das atividades produtivas deve considerar as éspecificidades setoriais, mas também seu inter-relacionamento multissetorial. Uma política de zoneamento agrícola, do ponto de vista macrorregional, além de levar em conta os tipos de solo, clima, topografia etc., deve ser acoplada a uma efetiva politica de minimização de custos de transporte, de armazenamento e, fundamentalmente, a uma politica de abastecimento micro e macrorregional.

Por sua vez, a "política" de localização industrial deve ser modificada em relação a seus atuais padrões. Hoje está lastreada por uma política generalizada de incentivos ao capital. É necessário, portanto, elaborar uma politica setorial que determine corretamente quais os setores e regiøes que devem ser disciplinados.

Para isso, uma política de localização industrial deve levar em conta os problemas técnicos de complementaridade industrial (por exemplo, as especificidades dos complexos agroindustriais ou de outros complexos) e a melhor utilização dos recursos naturais, entre outros aspectos. E bom ter presente que a indústria é um setor que contém muitas especificidades (técnicas, econômicas, de escala etc.) e, portanto, uma politica de localização deve, necessariamente, levá-las em conta.

Com respeito à relocalização industrial, deveria haver maior coordenação por parte do Governo federal, no sentido de, democraticamente, ouvir os interesses regionais. Com isso, é de nosso entender que uma política de relocalização ou descentralização industrial deverá levar em conta as especificidades de cada área e setor.

Por exemplo, o tratamento dessas questres nas áreas metropolitanas antigas não pode ser equivalente ao das áreas metropolitanas emergentes. Hoje, mesmo com o alto poder discricionário que tem, o Governo federal não possui uma política nacional de localização industrial que contemple aquelas especificidades. Ao contrário, ela tem sido discricionária e autoritária, valendo-se, antes, de critérios tecnocráticos ou de políticas de clientelismo.

Complementarmente, e de acordo com as determi. nantes principais da dinâmica da urbanização, deve-se pensar em acoplar a uma política de descentralização industrial políticas de localização de atividades do setor terciário, que são, direta ou indiretamente, complementares à atividade econômica e/ou necessárias ao aglome. rado urbano.

Passa ainda pelo problema da localização a controvertida questão dos critérios do uso do solo urbano, cujo debate tem aumentado devido à recente proposta do Governo federal em alterar a atual legislação; proposta que pode ferir ainda mais a autonomia municipal. A complexidade desse problema transcende os limites deste trabalho.

Cabe lembrar ainda que um planejamento urbano eficiente e que atenda prioritariamente ds populaçбes urbanas de baixa renda não pode ignorar o problema da especulação imobiliária. $O$ disciplinamento do uso racional do solo e o combate à especulação imobiliária constituem posturas decisivas para aquele atendimento popular.

Sem tais atitudes não há como praticar uma política habitacional e de infraestrutura acessível dquelas camadas. A que se pratica hoje no Brasil é a antítese da que deveria ser feita. Através da especulação e do desordenado uso do solo se pratica uma politica habitacional absurda e que resulta no seguinte: maior valorização especulativa de terrenos; maior custo de inversão e manutenção da infra-estrutura feita; maior distância de transporte; impossibilidade de melhor atendimento social (saúde, educação, segurança, lazer) etc.

\subsection{Finanças públicas: uma postura politica}

Com o processo de reabertura política ampliou-se o debate sobre a excessiva concentração dos recursos tributários na esfera federal. Este debate concluiu pela necessidade de uma profunda e urgente reforma tributária. Seus objetivos centrais seriam: restaurar a crônica situação das finanças estaduais e municipais; repor a autonomia dessas duas esferas institucionais $e$, ao mesmo tempo, restaurar o caráter público e social do atuais serviços "públicos".

Contudo, enquanto não se alcança essa medida, não se pode permanecer na imobilidade, decorrente da manutenção do atual Código Tributário Nacional, para solucionar os graves problemas urbanos. Enquanto for mantido esse impasse, julgamos que a alternativa mais conveniente é a de se tentar analisar a questão do ponto
de vista do gasto público.

Não se trata, contudo, de se repensar o gasto público tecnocraticamente. Isto tem sido feito durante os 20 
anos de autoritarismo. $O$ que se necessita urgentemente é abandonar a postura tecnocrática e adotar uma postura política que atenda ds efetivas necessidades e aos anseios democráticos do povo.

Caso contrário, os estados e, principalmente, os municípios continuarão a atuar basicamente pelo lado da receita pública, majorando impostos, taxas, tarifas e preços páblicos, acima, inclusive, do nível geral de preços, sem qualquer consideração sobre o poder aquisitivo do contribuinte.

Muito embora a tecnocracia tenha sido imposta pelo Governo federal, ramificou-se, via autoritarismo, pelos estados e municípios. Por isso é importante que se estabeleça uma profunda discussão e um trabalho de se repensar, politicamente, a aplicação dos recursos pablicos.

Durante esses anos todos, punidos pelas finanças públicas, as autoridades estaduais e municipais privilegiaram certos investimentos que, dadas as condiçoes de seu financiamento e a estreiteza de recursos, "exigiam" uma taxa de retorno, tal qual no setor privado. Por outro lado, várias atividades antes atendidas por uma reparticão pública passaram a sê-lo por empresas que, como tais, vieram tambem a comportar-se como empresas capitalistas, vendendo serviços públicos como se fossem privados, objeto de mercado e de apropriação particular. Não escaparam a essa conduta coisas como o fornecimento de água, energia elétrica, telefonia, serviços funerários, manutenção rodoviária e habitação popular.

O transporte coletivo, por exemplo, deixou de ser um serviço público para se institucionalizar como um do negocios mais rendosos da esfera municipal. Não há sequer uma política estadual para as tarifas municipais. Cada município tem sua própria política tarifária e chega-se ao absurdo de um ônibus em Campinas, com trajeto de distância quatro a cinco vezes menor do que algumas linhas da capital, possuir tarifa mais alta do que a de São Paulo.

Essa postura impede até mesmo que se pense em novas alternativas para esse importante serviço. Embora tenhamos consciência de que só com a descentralização financeira haverá recursos para se reprogramar esse serviço, ainda há muito a fazer, dentro das próprias limitações atuais.

A canalização e distribuição de água potável e a coleta de esgotos sanitários são tratados de modo diferenciado no Estado como um todo: parte dos municípios é atendida pela Sabesp e o restante pelos serviços municipais locais. Esse é um serviço que deve ter tratamento homogêneo pelo Governo estadual e que o planejamento urbano deve levar em conta, pois não se pode ter dentro do mesmo estado disparidades tão evidentes, como municípios que ainda não possuem rede de água potável nem rede de esgotos.

As tarifas também devem ser revistas, tendo em conta o contraste entre o custo do serviço e a renda diferenciada das famílias. $O$ ideal seria uma política de preços diferenciados, com tarifas progressivas, privilegiando-se as famílias de mais baixa renda.

O Governo do estado de São Paulo tem responsa. bilidade quase absoluta na geração e distribuição de energia elétrica. No entanto, as decisões para a expansão da rede de iluminação páblica estão sob a responsabili- dade dos municípios, responsáveis por grande parte dos investimentos da extensão das redes. Assim, os de menor arrecadação tributária privam seus contribuintes desse importante serviço. Portanto, dever-se-ia mudar a ótica dessa questão, tirando do município o peso desse investimento, sem, contudo, retirar-lhe a autonomia de decisão.

Por outro lado, os serviços de educação e saúde cujo aumento de demanda é induzido pela urbanização - contam com reduzidas dotaçðes orçamentárias e sofrem ainda do mal da pulverização de recursos. Paradoxalmente, o problema é agravado pela obrigatoriedade de aplicação de recursos, por meio de tributos vinculados, como no Fundo de Participação dos Municípios (FPM), onde 20\% dos recursos devem ser aplicados em Educação e Cultura, de preferência no ensino de $1^{\circ}$ grau. No caso do Estado, essa obrigatoriedade é integral, no que diz respeito à quota-parte estadual do salário-educação.

A tecnocracia, ao criar a obrigatoriedade de alocação de recursos em gastos de capital, em detrimento dos de custeio, tem proporcionado muitas obras públicas que, contudo, oferecem péssimo atendimento. E o caso de hospitais e escolas que, em que pese disporem de instalações, não dispõem de materiais de consumo e de pessoal convenientemente preparado e remunerado.

Ainda há que se lembrar que planejar significa também manter o que existe, e não apenas criar novos problemas. De outro modo, corre-se o risco de piorar ainda mais a manutenção do existente, ao mesmo tempo em que se comprometem as metas a serem atingidas pelo planejamento.

O grave problema das "cidades-dormitório" também deveria ser reformulado, uma vez que suas receitas municipais são insuficientes para solucionar seus problemas mais simples. Que dizer então da responsabilidade adicional de tentar resolver problemas que são causados, acima de tudo, por questoes externas ao limite dos seus municípios? A situação financeira desses municípiọ tende, a longo prazo, ao agravamento, dado que parcela significativa de sua população trabalha em outros municípios, ali gerando rendas, empregos e impostos.

Essas populaçōes, ao residirem em municípios de menores recursos e rendas, potenciam as dificuldades financeiras desses municípios, pois constituem um agrupamento de pessoas de baixa renda e, portanto, de reduzida capacidade de contribuição de impostos.

Por possuírem baixos rendimentos, sã̃o carentes de necessidades básicas, como saúde, habitação, saneamento básico, pavimentação etc. Em face das questōes ora levantadas, pressionam fortemente as autoridades locais, que são impotentes para suprir essas necessidades, o que deteriora ainda mais as condiçðes de vida dessa população.

Como enfrentar essa questão? Dever-se-ia pensar em formas de redistribuição estadual macrorregional dos recursos. Por exemplo, cotejando-se a arrecadação, renda, emprego e domicílio gerados em cada espaço, com a redistribuição espacial das necessidades básicas das populações de baixa renda, explicitadas especialmente.

Afora as questões antes levantadas, o planejamento urbano deve estabelecer uma metodologia que concilie 
as responsabilidades em cada esfera de Governo, ao mesmo tempo em que deve utilizar da melhor maneira possível os recursos disponíveis. Deixemos claro, porém, que estamos propondo apenas uma reorientação do gasto páblico entre os três níveis de Governo em termos cooperativos, escapando-nos, no momento, a discussáo da questão mais profunda que é a Reforma Tributária.

\section{QUESTÓES PARA UM NOVO DIAGNOSTICO}

Por que o planejamento urbano não tem tido maior eficácia? Certamente, não por falta de planos urbanísticos gerais, planos diretores e outros planos produzidos em quantidade nas últimas décadas. Além de apoio político, institucional e financeiro, sua coerência, diante de uma dada realidade, requer, antes de tudo, um correto e abrangente diagnóstico.

Contudo, previsðes precárias como a de que havera uma "explosão urbana no ano 2000", vaticinadas para várias áreas metropolitanas - como a do México, para a qual se estima 30 milhōes de habitantes e para a de São Paulo, que viria a ter 25 milhões - em função de "tendência", colaboram para manter a equivocada maneira de diagnosticá-las.

Propomos aqui não o abandono do estudo histórico (para tendência), mas sua revisão, no sentido de incorporar-lhe as mudanças que vão ocorrendo não só no espaçoobjeto do diagnóstico mas também em outros espaços e outros setores que podem alterar, nesse espaço-objeto, a tendência até então observada.

Como se tentara mostrar no item 4, os cortes periodicos deverão ser feitos, sempre que possível, não só para obter os "resultados liquidos da década", como tem sido a utilização censitária, mas sim para perceber a natureza e a dinâmica do processo de urbanização, e levar em conta as transformaçðes fundamentais ocorridas no período. Entre estas, devem ser examinadas as alteraçס̃es na dinâmica da produção e do emprego; nos níveis setoriais da produtividade do trabalho; nos fluxos migratórios e suas causas; na política econômica e políticas urbanas.

No que tange ao diagnóstico urbano municipal, deve-se estudar o processo de apropriação privada do solo urbano, sua utilização e a variável que inexoravel. mente o acompanha, a especulação, que tem sido a principal responsavel pela ausência de melhor atendimento às necessidades sociais das populaçðes da periferia de nossas cidades.

Estas transformaçðes vêm sendo pouco consideradas pelos planejadores urbanos. Exemplifiquemos o problema através de alguns fatos ocorridos nos espaços de São Paulo e em espaços rurais ou urbanos de outras regizes, que não o da area metropolitana ou do estado de São Paulo, mas que geraram efeitos importantes tanto nessa área como nos principais núcleos urbanos do estado:

- as grandes áreas do Nordeste e a contínua expulsão rural naquela região geram fluxos migratórios que, desde há muito, demandam os mercados de trabalho do estado de São Paulo, contribuindo fortemente para sua expansão demográfica, notadamente em sua área metropolitana;
- a erradiação do café no Paraná, durante a década de 1960, gerou forte fluxo migratório, demandando outras áreas rurais e urbanas do Pars e boa parte dele se dirigiu ao estado de São Paulo;

- a intensificação capitalista no complexo soja-trigo, no extremo sul do País, diminuindo a minifundização naquela região, promoveu também importante fluxo migratório que, embora demandasse várias regiðes do País, encontrou acomodação parcial no estado de São Paulo;

- as transformações tecnológicas que ocorreram na própria agricultura de Sáo Paulo alteraram sua estrutura de emprego e aumentaram a quantidade de trabalhadores temporários, principalmente nas culturas de algodão, cafe, cana-de-açúcar e laranja. Esses trabalhadores "os bóias-frias" - produzem no setor rural, mas são obrigados a residir na área urbana, repercutindo fortemente no crescimento periférico de várias cidades médias do estado de São Paulo;

- a própria dinâmica cíclica da indústria paulista tem gerado, em sua expansão física, uma série de transformações qualitativas na estrutura do emprego urbano, de foma direta $e$ indireta.

Dentro do proprio setor serviços, podemos distinguir dois tipos de fenômenos de longo prazo que decorrem das transformações por que passam as maiores aglomeraçðes urbanas. Parte desses fenômenos constitui efeitos positivos, que decorrem de alterações da demanda pessoal. Isso repercute positivamente na estrutura da oferta de serviços, reajustando tambem o nível e a estrutura do emprego. Contudo, surgiram tambem efeitos negativos, repercutindo na constituição de ampla e crescente marginalidade urbana, promovendo a "inchação" do terciário, também chamada de "proliferação de serviços informais".

Esses exemplos reforçam nossa preocupação de que no diagnóstico histórico, e também na prospecção para o planejamento, a periodização constitui problema dos mais complexos. Ou seja, fenômenos com dinâmicas específicas, ocorrendo em espaços distintos e em períodos distintos, ensejam num mesmo momento diversos efeitos sobre um mesmo espaço urbano.

Note-se que esses efeitos - como se verá no item 4 - tanto se manifestam no nível do emprego quanto no da renda. Vale dizer: sua explicitação demográfica repercute também na ótica da demanda por novas necessidades sociais e pressiona as finanças públicas para novos atendimentos. Como se vê, não se pode pura e simplesmente fazer projeçðes das tendências demográficas "dos altimos 20 anos" sem se dar conta daqueles fenômenos.

No que se refere à questão do espaço, deve-se considerar suas grandes transformações de longo prazo e a insuficiência da regionalização "político-administrativa", como a do tipo "município de São Paulo", da mesma forma que é necessário ter consciência da complexidade envolvida ao se tomar como corte analítico um agregado do tipo "Grande São Paulo".

Essa complexidade decorre do fato de que esse espaço maior - a Grande São Paulo - compreende espaços 
com graus diversos de heterogeneidade, como as áreas que constituem espaços que funcionam predominantemente como cidades-dormitório, e outros que têm como função primordial a produção industrial. Evidentemente, cada um desses espaços apresenta dinâmicas distintas de expansão, assim como problemáticas distintas no que tange à questão da finança e do gasto públicos.

Por outro lado, a área do estado de São Paulo que exclui sua região metropolitana hoje é administrativamente dividida em 11 "regiōes". Essa divisão, para fins de diagnóstico, deve ser revista tendo em conta suas principais diferenças, pois nem sempre uma divisão administrativa atende aos requisitos exigidos por um bom diagnóstico.

Uma polftica que procurasse promover um zoneamento da produção agrícola (e de parte de sua transformação industrial) do estado de São Paulo seria da maior relevância para um planejamento mais eficaz, não só da área metropolitana, como também dos principais centros urbanos do estado, em face dos problemas de abastecimento, de economia de custos de transporte e de meioambiente. Os conflitos recentes entre a política federal do programa do álcool de cana do estado de São Paulo e a do Govemo estadual (ecologia e produção de alimentos, entre outros) constituem exemplo da complexidade da questão do zoneamento agroindustrial.

Outra ordem de sugestões que colocamos neste topico é a de se fazer um diagnóstico específico de alguns centros urbanos, a fim de estimar seus efetivos potenciais de ocupação, com atividades e pessoas.

Essa avaliação seria baseada não só pelo quadro atual, mas também pelas previsð̃es que pudessem ser feitas através do estudo dos principais determinantes da dinâmica urbana. Detectados pontos de saturação, que originassem esgotamentos relativos do potencial daquele espaço urbano, o novo planejamento poderia estimar a necessidade de investimentos e a alocação de recursos para eliminar ou atenuar aquela saturação.

Saturações que na maioria dos casos são fictícias. Produtos das especulaçðes urbanas e do mau aproveitamento dos recursos surgem na forma de aparente falta de solo urbano para núcleos habitacionais populares, aparente esgotamento de recursos hibridos, condições ambientais desfavoráveis etc. Em tais casos, requer-se mudança na forma política e técnica de se analisar o espaço, a fim de se propor soluções técnicas democraticamente discutidas.

Assim, se a avaliação do potencial de um espaço urbano constatasse sinais de sua exaustão relativa, os poderes constituídos deveriam estudar e propor soluçðes que, necessariamente, implicariam novas estruturas de impostos, taxas e preços públicos diferenciados.

Essa diferenciação deveria ser capaz de promover nova acomodação da população e das atividades econômicas, no próprio espaço municipal ou em municípros proximos. Para isso seriam estabelecidos, através da avaliação de potencial urbano, sistemas fiscais "punitivos e incentivadores", a fim de que se pudesse promover melhor alocação espacial das atividades e das pessoas.

Dentro do próprio município, isto poderia ser feito através de políticas de urbanização que utilizassem melhor as alternativas de "concentração vertical". $\mathrm{Ou}$, ainda, através de medidas fiscais altamente onerosas tanto para a manutenção de terrenos ociosos, nas áreas mais próximas, quanto para a abertura de loteamentos ou implantação de núcleos habitacionais desnecessariamente distanciados.

Isto também poderia ser conduzido, no âmbito de um conjunto de municípios, através de diagnóstico e planejamento intermunicipais que objetivassem melhor alocação espacial da região.

\section{PRINCIPAIS DETERMINANTES DA DINÂMICA URBANA NO ESTADO DE SÃO PAULO}

Nossa proposta, em síntese, é integrar nos estudos sobre urbanização a interação das dinâmicas dos setores produtivos: a ação da atividade agrícola, com seus efeitos positivos e negativos sobre o mundo urbano; a ação que o setor industrial exerce sobre o terciário e sua recíproca; a expansão e a diferenciação "autônoma" do terciário, que decorre do próprio fenômeno da expansão do mundo urbano, graças ds modificaçð̃es dos níveis de renda e de emprego.

Como se sabe, o setor agrícola exerce impacto diferenciado sobre o urbano, gerando efeitos positivos e negativos sobre ele. Positivos ao demandar mais atividades aos setores econômicos urbanos (industriais, comerciais, financeiros etc.), em decorrência de sua expansão e modernização.

Contudo, a agricultura também gera seus efeitos perversos. Ao intensificar sua tecnologia, não apenas enseja um aumento no êxodo rural. Transforma também a estrutura de sua necessidade de mão-de-obra, diminuindo o trabalho permanente e aumentando o temporário. Este último, vulgarmente conhecido por trabalhadores "bóias-frias", embora exerçam seu trabalho no mundo rural, são obrigados a residir no mundo urbano.

Como se verá adiante, este fenômeno tem grandes implicações na expansão das periferias de muitas cidades, aumentando-lhes a miséria e pressionando o atendimento público por suas demandas sociais.

No que se refere ao setor industrial, cabe lembrar que ele tem sido melhor estudado que os demais e, por isso mesmo, seus impactos no mundo urbano são melhor conhecidos e detectáveis. Basicamente se manifesta, direta $e$ indiretamente, por seu impacto na renda e no emprego urbanos. Contudo, existem outras questōes que devem ser examinadas, como, por exemplo, a dos custos reais derivados de uma implantação industrial em determinada área (habitação, transporte, infra-estrutura, serviços de saúde etc.).

E desnecessário enfatizar a importância de que se reveste o estudo ao "setor serviços", principalmente no estado de São Paulo, onde é responsável por cerca de $50 \%$ do emprego.

O terciário é um setor que contém muitas especificidades, entre as quais cabe citar:

- o fato de que sua dinâmica é, em parte, induzida pelos setores da produção material e, em parte, decorrente das respostas que têm que dar às pressões da expansão da massa humana que vive em seu contexto; 
- nele estão presentes o setor privado e o público. Este altimo, em certas áreas urbanas, tem papel importantíssimo no nivel da renda e do emprego urbanos;

- em termos de emprego, existe apreciável contingente (serviços domésticos) onde é marcante a presença femi. nina e que não está vinculada diretamente ao ritmo de crescimento da economia.

O estudo destas atividades tem padecido de grande deficiência metodológica $e$ informativa, haja vista a precariedade dos censos de serviços e das contas nacionais. Estes dois obstáculos têm sido os principais responsáveis pela ausência de trabalhos analíticos de maior envergadura sobre o terciário.

Alguns esforços recentes de pesquisas sobre o mercado urbano de trabalho, operando sobre as PNADs e tabulações do censo demográfico, têm avançado o estudo da estrutura do emprego terciário. Indiretamente, têm também fornecido meihor visão das modificaçōes ocorridas na estrutu ra produ tiva terciária.

Conscientes dessas preocupaçбes, apresentaremos e discutiremos as três partes deste item. Na primeira, resumiremos as formas de impacto e geração de efeitos que os fatores externos e internos exerceram sobre a dinâmica urbana do estado de São Paulo. Na segunda, discutiremos os que se originaram fora do espaço do estado de São Paulo, decorrentes de dinâmicas específicas a cada região ou da dinâmica nacional, mas originados em espaços localizados fora do estado de São Paulo.

Como exemplo, pode-se formular a seguinte questão: que efeitos gera sobre o urbano de São Paulo, uma seca no Nordeste? Ou, ainda, que efeitos podem ser gerados no espaço rural e, posteriormente, no espaço urbano de São Paulo, uma intensificação tecnológica na agricultura do extremo sul do País, ao concentrar sua estrutura fundiária e acelerar suas migrações?

O terceiro tópico abordará os determinantes da dinâmica urbana do estado de São Paulo que são gerados dentro do seu próprio espaço. Por exemplo, as transformações da agricultura paulista, que repercutem no seu espaço urbano; a expansão da indústria paulista e suas repercussðes sobre o emprego e a renda urbanos; a demanda derivada por serviços, gerados por expansão industrial etc.

É provável que, através do aparelho informático atual, se conseguisse aplicar a metodologia aqui proposta sobre os dados mais recentes e se formulasse alguns modelos formais que "explicassem" a dinâmica atual da urbanização paulista.

No entanto, isto seria insuficiente para a correta compreensão do fenômeno e, ainda, de reduzida observação empirica. $\mathrm{O}$ que se requer é uma profunda pesquisa histórica periodizada - em sentido geral - de 1930 a 1970 , mas subperiodizada para permitir analises especfficas de setores e de determinadas variáveis.

Isto se justifica pelo fato de que a evolução urbana em São Paulo atravessou periodos bastante diferenciados e, em cada um deles, seus determinantes também sofreram variações, que certamente implicaram efeitos também diferenciados sobre a dinâmica dessa urbanização. Por outro lado, há que se ter presente o fato de essa dinâmica não se manifestar igualmente por todas as principais regiões urbanas do estado. Assim, deve-se analisar, no tempo, suas especificidades espaciais.

E nessa perspectiva histórica que apresentaremos os tópicos seguintes, isto $\hat{e}$, dentro dos marcos temporais do período 1930-70. Essa análise, assim entendemos, será necessária tanto para a elaboração do diagnóstico como para a própria formulação do planejamento.

\subsection{Efeitos gerados pelas principais variàveis determinantes da dinâmica urbana}

Resumidamente, os principais fatores externos e internos, que atuam sobre a dinâmica urbana do estado de São Paulo, geram os seguintes tipos de efeitos: os demográficos propriamente ditos; os que atuam sobre a estrutura e o nível do emprego; os que modificam o nível e a estrutura da renda e da produção urbanas; os que alteram o potencial gerador de tributos em um determinado espaço urbano; e os que geram novas demandas sociais básicas sobre um espaço urbano, pela interação dos efeitos demográficos, da renda e do emprego.

A relevância da temática e a ausência de estudos abrangentes impõem a necessidade de se fazer a análise histórica desse processo de urbanização, cujo marco temporal e o período de 1930-70. Essa periodização é assim demarcada por compreender a transição do padrão de acumulação de capital que caracteriza a etapa "primário-exportadora", que cede lugar, após a crise de 1929, a outro padrão, cuja característica principal é a da industrialização.

A elaboração desse estudo seria de extrema valia, dado que permitiria uma avaliação retrospectiva ainda que aproximada - da ação daqueles fatores internos e extemos sobre o acelerado processo de urbanização por que passou o estado de São Paulo. Vejamos os principais tipos de efeitos a que estamos nos referindo.

1. Os efeitos demográficos. Há que se reavaliar a série histórica demográfica, não apenas para rever seus resultados e modificaçōes paramétricas, mas para analisar de que modo os fatores internos e externos, a que nos referimos, atuaram sobre as variáveis demográficas. Esse exame fomecerá importantes informações e análises sobre os efeitos que geraram alterações na taxa de natalidade, na de mortalidade, na estrutura etária, na estrutura cultural (alimentação, educação, higiene etc.), no padrão de saúde da população etc.

2. Efeitos sobre o nivel e a estrutura do emprego. Neste item, as variáveis seriam examinadas tanto em termos de seu impacto quantitativo sobre o mercado de trabalho quanto pelas modificações qualitativas exercidas sobre sua estrutura. Levar-se-iam em conta as alterações de curto e longo prazos que modificaram as condições de ascensão do trabalho: nível de qualificação, nível salarial, padrão de vida etc.

3. Efeitos sobre o nivel e a estrutura da renda e da produção urbanas. A análise se pautaria pelo exame dos impactos (contração ou expansão) na produção e na renda urbanas, bem como sobre as alterações de curto e longo prazos da estrutura de produção e da renda, particular- 
mente no que se refere ao perfil distributivo da renda urbana.

4. Efeitos sobre a capacidade geradora de tributos. Este efeito decorre de alteraçóes no nível e na estrutura da economia urbana (modificações qualitativas, expansão ou contração) e do seu contingente demográfico. Ambos podem ampliar o nível e alterar a estrutura da receita pública municipal ou de uma regiāo. Seu exame objetivaria avaliar a capacidade geradora de tributos de um novo contingente de imigrantes ou de novas indústrias que se instalassem em determinado espaço urbano.

5. Efeitos sobre o gasto puiblico. Este efeito e a contraface do anterior. Aqui se procurará examinar as novas demandas sociais e de infra-estrutura, geradas sobre um determinado espaço urbano, pela vinda de novos imigrantes e trabalhadores ou pela política de atração de novas atividades econômicas. Especificamente, indagar que novas demandas de saúde, saneamento, transportes, comunicações, habitação, pavimentação. etc. surgiram em função daqueles eventos.

Finalmente, dever-se-ia analisar a interação dos dois últimos efeitos, o que nos permitiria uma avaliaçãosíntese dos efeitos liquidos (positivos ou negativos) que cada variável de impacto desencadeou sobre a receita e o gasto público. Com isso, o planejamento de um espaço urbano poderia contar com critérios mais apurados para promover a atração ou rejeição de determinadas atividades econômicas, e melhor adequação social das finanças públicas, por exemplo, diante de uma expansão demográfica originada de imigraçð̃es de trabalhadores de baixa renda.

\subsection{Fatores não localizados no estado de São Paulo}

$O$ estado de São Paulo é responsável por cerca de $1 / 4$ da produção agricola nacional, por $58 \%$ da produção industrial e por $1 / 3$ da geração de serviços, o que o converte no maior centro de atração e irradiação econômicosocial do País. No estudo aqui proposto, cabe-nos examinar alguns aspectos de sua capacidade de atraç̄o em relação às demais regióes do País. É em função dessa capacidade de atração que ganha maior relevância o estudo da dinâmica sócio-econômica das demais regiðes do País e de suas principais mudanças estruturais.

\subsubsection{Fatores decorrentes da estrutura e da dinâmica econômico-social}

A heterogeneidade das economias regionais do País obriga-nos a tomar atenção para esse fenômeno e não tratar o País como uma simples "média estatística" ou agregado econômico-social. Certos movimentos e transformações em determinada região podem ter repercussão relevante em São Paulo. Dar que não se pode, no estudo da dinâmica urbana deste estado, ignorar as linhas gerais da dinâmica regional brasileira.

Em que pese à multiplicidade desses eventos, limitar-nos-emos ao exame do principal deles, que é o das migraçðes inter-regionais. Estas decorrem, fundamentalmente, do movimento das economias regionais e das transformaçðes (ou da falta delas), ocorridas nas suas relaçð̃es de produção (técnicas, econômicas e sociais), além das causadas por eventos.naturais de grande porte como as secas no Nordeste.

No plano histórico do estado de São Paulo, no periodo 1870-1925, predominaram as imigraçðes européias (e japonesa, entre 1908 e 1930), que permitiram a formação dos mercados de trabalho cafeeiro e urbano. No decorrer da década de 1920, os fluxos migratórios nacionais - particularmente de nordestinos e mineiros - para São Paulo, superaram largamente os de estrangeiros e aumentaram fortemente durante o período de 1930-70.

Essa capacidade de atração e de acomodação dos fluxos migratórios não foi exclusiva do estado de São Paulo. A abertura agrícola do norte do Paraná durante o período de 1930 a 1950; a abertura da fronteira agrícola do Centro-Oeste e do Maranhão, nas décadas de 1950 e 1960 e, posteriormente, a ocupação amazônica que se processa a partir da década de 1970, constiturram importante desafogo para esses fluxos, pois sua alternativa teria sido a de "inchar" ainda mais os dois maiores centros urbanos do Paŕs, que são o Rio de Janeiro e São Paulo.

Em suma, enquanto a fronteira agrícola esteve em processo de dilatação, permitiu importante "acomodação" social para imensas levas de migrantes nacionais.

0 estado de São Paulo recebeu importante fração dessas levas. Contudo, a tecnificação de sua agricultura converteu-o em "exportador" de parte de sua própria população rural. Os fluxos para o estado de São Paulo, acumulados até 1970 , totalizavam uma entrada de nacionais superior a 3 milhões de habitantes, mas indicava sardas em torno de um milhão de paulistas.

Esses fluxos migratorios contemplam amplo espectro regional. Minas Gerais é o estado de maior emigração: até 1970 , expulsou liquidamente $25 \%$ de sua população. Até aquela data, as perdas líquidas foram importantes para o Rio Grande do Sul (9\%), Santa Catarina $(4,5 \%)$ e Espírito Santo (10\%). 0 Nordeste (excluindo - Maranhão) perdeu, em média, $14,4 \%$ de sua população.

Nas décadas de 1960 e de 1970 as transformaçōes agrícolas por que passavam o Rio Grande do Sul, Paraná, São Paulo e o Centro-Oeste ampliaram os focos migratórios, reforçados ainda pelo problema fundiário do Maranhão, que também se convertia em expulsador de populações rurais. Em resumo, os grandes centros urbanos foram ainda mais pressionados, dada a queda da capacidade de retenção populacional dessas áreas.

Por isso, entendemos que o estudo das migraçós é absolutamente necessário para a elaboração do diag. nóstico para o planejamento urbano do estado de São Paulo, e que devem ser examinadas em suas duas vertentes:

1. Migrações decorrentes do desejo de maior ascensão social. São as migraçðes mais vinculadas à área urbana e representam o desejo e a possibilidade de maior mobilidade social de certas fraçðes populacionais. Sð̃o, geralmente, de habitantes de outros centros urbanos (capitais ou não) com alguma ascensão na pirâmide social e que desejam atingir níveis mais elevados. Não 
conseguem, em face das condiçðes do meio em que vivem (espaços urbanos de menor poite), obter os meios que julgam necessários para aquela melhoria: melhor nível de educação, de cultura, de remuneração, de lazer etc. Não é difícil, com as estatísticas e com o nível da pesquisa demográfica atuais, estimar-se esses fluxos.

2. Migraf̧ões por expulsão. Decorrem tanto de fatores estruturais quanto de fatores naturais episódicos, como as secas nordestinas. A precariedade agrícola dessa região, a intensidade maior de uma seca e a rigidez do acesso à terra impedem que amplas massas humanas tenham outra alternativa rural na própria região. Assim, são expulsas de seu próprio meio e forçadas a emigrar para outras regiðes.

As especificidades regionais mostram que a expulsão decorrente da manutenção da estrutura fundiária ou de sua mudança são diferenciadas. Por exemplo, a rigi$\mathrm{dez}$ da estrutura fundiária no Nordeste é um foco estrutural permanente de expulsão de mão-de-obra. Entretanto, também no extremo sul há expulsão: à medida que o capitalismo intensifica sua ação no campo, transforma sua estrutura fundiária, pelo aumento do processo de concentração da propriedade e amplifica a expulsão do minifundista camponês.

Cabe lembrar a expulsão rural decorrente da inovação tecnológica na agricultura nacional. Seu resultado tem sido o de elevar a produtividade do trabalho em proporção muito maior que a da terra, diminuindo a quantidade de trabalho necessário e permanente, e modifica sua necessidade estrutural, ampliando a de trabalho temporario.

Uma quarta forma expulsadora decorre da própria dinâmica econômica regional. Se o crescimento da economia de uma dada região é débil, a taxa de expansão do emprego é mínima, e isto também aumenta os fluxos emigratórios.

\subsubsection{Fatores decorrentes da política econômica}

As políticas econômicas postas em prática pelas demais unidades da Federação podem gerar impactos no processo de urbanização do estado de São Paulo. Contudo, seus prováveis efeitos são de menor alcance. Assim, restringimo-nos ao exame do impacto das principais políticas econômicas do Governo federal.

1. Politica fiscal e tributária. O centralismo fiscal emanado da reforma tributária de 1967 prejudicou estados e municípios. Assim, a atual estrutura tributária e suas virtuais modificaçðes constituem ponto importantíssimo a ser considerado no diagnostico e no planejamento urbano paulista.

O centralismo é de tal ordem que chega a sobrepor sérias determinaçōes sobre o investimento público dos espaços urbanos do estado de São Paulo, comprometendo seriamente os graus de liberdade no planejamento do gasto público do estado e dos municípios.

2. Política salarial. Sua análise pode ensejar subsídios importantes em termos da determinação de alterações do perfil distributivo da renda. Mais uma vez, nos defrontamos, aqui, com a questão fundamental dos escalðes da pirâmide social urbana que detêm os mais baixos níveis da renda familiar. Esse escalão, ao mesmo tempo que tem exígua capacidade geradora de tributos, tem grande demanda de necessidades sociais básicas.

3. Politicas de descentralização. Estas poderiam afetar sobremodo o processo de urbanização se, efetivamente, fossem postas em prática. Através delas, o Govemo federal tenciona descentralizar parte da massa econômica concentrada hoje em São Paulo, particularmente em sua indústria.

Suas medidas práticas, contudo, têm sido escassas, e sua eficácia bastante duvidosa.

4. Politicas de desenvolvimento regional. Estas têm eficácia maior que as anteriores. Durante as últimas décadas foram institurdas as primeiras políticas de desenvolvimento regional, que se consubstanciaram numa política de incentivos ao capital para empresas que se instalassem nas regiões Norte e Nordeste.

A expansão industrial verificada nessas áreas foi relevante, impedindo o avanço maior da concentração industrial em São Paulo. Os efeitos positivos derivados dessa industrialização sobre os espaços urbanos daquelas áreas são bons para São Paulo, pois, assim, parte do fluxo emigratório (pequena, é verdade, dado o baixo grau de emprego qualificado gerado) é retida nas pró. prias regioes de origem.

5. Politica agrária. Ainda que a reforma agrária tenha sido contida pelo Governo federal, o exame das poucas medidas adotadas e necessário, a fim de se estimar o impacto que deixa de atingir o setor urbano, pela manutenção, no campo, de populações beneficiadas. A reforma agrária constitui a mais importante questão a ser estudada, também como instrumento de uma política de urbanização. Este fato, obviamente, deriva da hipótese de se conseguir deter fluxos migratórios do tipo ruralurbano, mantendo-os como rural-rural, através da política de acesso à terra.

6. Políticas públicas. Nestes 20 anos de Governo autoritário, a política econômica federal não deu a necessária ênfase às questões atinentes às políticas públicas (saneamento, educação, habitação, saúde etc.). Contudo, seria útil o exame dos efeitos que elas têm gerado, no sentido de melhor adequar os fluxos migratórios interregionais. Esse estudo seria valioso tanto para o Governo federal - no caso de haver radical mudança na política económica - quanto para o estado de São Paulo, em seu planejamento urbano e social.

\subsection{Fatores localizados no estado de São Paulo}

$O$ exame destes fatores deve partir do momento da ruptura da crise de 1929, quando se altera o padrão de acumulação de capital predominante ("primário-exportador"). A partir dar, a indústria e as demais atividades urbanas constituiriam os principais determinantes da renda e do emprego em São Paulo. O período de 1930 a 1960, particularmente a década de 1950 , revelou um excepcional ritmo de expansão urbana para a economia paulista. Contudo, como já vimos, não basta $v$ estudo da expansão industrial, demográfica e urbana. Assim, há 
que se examinar as dinâmicas dos vários segmentos produtivos para tentar estimar os efeitos que cada um deles gerou no processo de urbanização do estado de São Paulo.

\subsubsection{Fatores decorrentes da estrutura e da dinâmica econômico-social}

Os principais fatores intemos serão aqui especificados por suas origens setoriais.

1. Fatores decorrentes do setor agricola. Num primeiro grupo de fatores situam-se os que decorrem do maior avanço técnico do agro paulista e de profundas alterações da estrutura produtiva. Essas mudanças, a partir de fins da década de 1950, geraram inumeros efeitos positivos e negativos nos principais centros urbanos do estado, particularmente na Grande São Paulo.

Resumidamente, são os seguintes os efeitos positivos, decorrentes dessas transformações: maior demanda do setor industrial, para fomecimento de novos insumos e equipamentos; maior demanda do setor terciário, em termos de serviços financeiros, de armazenagem, de transporte, de comercialização etc. Um outro grupo de efeitos decorrentes da agricultura é o derivado da expansão de suas exportações e que tambem implicou demandas novas e adicionais àqueles setores.

Contudo, esse avanço técnico na agricultura também gerou efeitos perversos sobre o urbano paulista, dado o enorme êxodo rural produzido pelo grande avanço na produ tividade do trabalho.

Além disso, essa inovação, ao alterar a estrutura do emprego rural, aumentando o volume de trabalho temporário, ampliou para $500 \mathrm{mil}$ trabalhadores o contingente de "bóias-frias" que, como se sabe, embora produza no setor rural, obrigado a habitar as periferias das cidades.

Por sua vez, essa "inchação" urbana aumentou ainda mais os encargos sociais que recaem sobre as municipalidades.

Contudo, nas regiōes agrícolas em que não houve avanço técnico significativo, a falta de transformações tecnológicas e da estrutura produ tiva promovem também o êxodo rural, pela queda do rendimento do solo e da renda do trabalho. Este é um dos mais graves paradoxos do subdesenvolvimento.

2. Fatores decorrentes do setor industrial. Muito embora a indústria tenha sido o compartimento produtivo mais estudado até hoje, suas análises não ultrapassam - salvo raras exceções - os chamados efeitos diretos "para trás e para frente" da produção industrial sobre os demais setores produtivos.

Em determinados segmentos industriais, no entanto, os efeitos indiretos de emprego podem igualar ou mesmo superar os efeitos diretos. Por exemplo, o segmento automobilístico é um dos maiores geradores indiretos de emprego, através das redes de comercialização (veículos, peças, combustiveis), financiamento, reparos mecânicos, indústrias de produção de peças de reposição, repartições de fiscalização e licenciamento de veículos, lavadores e guardadores de carros etc.

A estimativa da geração indireta de renda e de emprego urbanos pela indústria é requisito importante da metodologia aqui proposta. No caso deste setor, é possível avançar algo, mediante a utilização das matrizes de insumos-produto hoje dispon ́veis no País.

Trabalho adicional deverá ser feito junto à indústria de construção civil, até hoje pouco estudada e que é a principal empregadora urbana direta de mão-de-obra. Portanto, o exame da dinâmica do setor industrial requer certo aperfeiçoamento analítico para que se possa estimar melhor seu impacto sobre o setor serviços.

3. Fatores decorrentes do setor terciário e da própria urbanização. A terceira fonte de fatores determinantes do processo de urbanização decorre da dinâmica do setor terciário e da própria dimensão que a urbanização atinge em determinado espaço. São efeitos geradores de novos efeitos, derivados da expansão do próprio terciário e da expansão da massa crítica urbana.

Lembremos que o terciário tem, em grande medida, uma dinâmica reflexa. Sua oferta reflete as demandas derivadas da indústria e da agricultura. Contudo, o terciário guarda uma "certa autonomia". Seus segmentos de transportes e finanças constituem atividades que, em grande medida, são reflexas dos compartimentos produtivos. Outros, porém, guardam graus variáveis de dinâmica reflexa e "autônoma". Por exemplo, a atividade do comércio cresce, em parte, como complemento das atividades produtivas de mercadorias e, em parte, pela pressão decorrente da própria expansão urbana.

A produção de serviços técnicos depende tanto de uma dinâmica reflexa (como os serviços técnicos exigidos pela expansão agrícola e industrial), como tambem de serviços especializados, que decorrem da expansão do núcleo urbano. Nas áreas metropolitanas, este fenômeno é mais facilmente detectado, e, hoje, a disseminação da "informática de consumo" constitui seu melhor exemplo.

Os chamados serviços pessoais, parte do transporte coletivo, serviços de educação, de saúde, de lazer, de alimentação etc., constituem atividades terciárias que estão muito mais vinculadas à própria expansão do núcleo urbano e das decisōes políticas de execução do gasto publico. Poderiam, sem grande violentação, ser chamados de serviços vinculados à "dinâmica própria" do setor terciário, ou seja, uma dinâmica decorrente de expansão do nível de urbanização.

Por último, tratemos de uma característica importante que tem o setor terciário de possibilitar efeitos compensatórios no nível de emprego urbano, durante as diferentes etapas cíclicas depressivas ou de auge da economia. Quando a recessão atinge mais intensamente 0 setor industrial e, particularmente, a construção civil, o terciário promove parcial compensação, expandindo o emprego em atividades de menor remuneração, em serviços pessoais, especialmente no emprego doméstico.

Isto repercute negativamente nas finanças públicas municipais, dado que essa compensação do emprego é precária e de baixa remuneração, causando aqueles efeitos negativos a que antes já nos referimos, atrofiando a receita pública e demandando expansão do gasto publico.

Ao contrário, nas fases de auge do ciclo, em que o emprego industrial - e especialmente o da construção civil - aumenta, as pressões sobre o mercado de traba- 
lho menos qualificado podem resultar em tendências de melhoria do salário.

$O$ período recente mostra que tais pressōes positivas (tanto para os assalariados quanto para as receitas municipais) são de curta duração, e são mais que compensadas com fluxos imigratórios adicionais, estimulados pela "vinda ao Eldorado".

\subsection{Fatores decorrentes da politica econômica}

Referir-nos-emos, neste tópico, às políticas postas em prática no estado de São Paulo pelas instâncias estaduais e municipais paulistas.

1. Politicas de descentralização ou "interiorização". Entendemos como necessário o exame das principais medidas que, intencionalmente ou não, resultaram em impactos efetivos sobre a urbanização do espaço paulista, que exclui o do município da capital. São necessários também a análise e o mapeamento cronológico e espacial de uma série de medidas (inclusive as do tipo meramente persuasivo) intencionalmente voltadas para a descentralização. Deverão ser estudadas as seguintes:

a) políticas de construção rodoviária e de estradas vicinais;

b) polfticas de descentralização de obras de infra-estrutu ra social, como a criação no interior do estado de escolas especializadas ou de nível superior, de hospitais regionais, equipamentos de lazer etc.;

c) políticas efetivas de descentralização administrativa de órgãos públicos;

d) políticas de descentralização de atividade econômica; e) politicas de desenvolvimento regional, como a do Vale do Ribeira.

2. Politica fundiária. Embora tenham sido poucas as medidas de política fundiária tomadas pelo Governo estadual, desde fins da década de 1950 , seria útil exami- nar seus efeitos, principalmente no que se refere à criação de empregos rurais e de interceptação de migraçóes do tipo rural-urbano. A atual administração estadual conta com nova política fundiária e o exame de sua viabilidade poderia constituir elemento útil para o planejamento.

3. Politica de regionalização. Vigentes há menos de 20 anos, sem São Paulo, essas políticas devēriam ser examinadas - tanto as que instituíram a região metropolitana de São Paulo e as demais regiōes administrativas do estado quanto as que devem seu nascimento a iniciativas das prefeitu ras municipais de determinadas regiðes.

4. Politicas de atração municipal de investimentos. São as implementadas por inúmeros municípios paulistas, com o objetivo principal de atrair novas indústrias para esses municípios. Operam na base de vários incentivos: construção de distritos industriais; impostos e taxas diferenciados ou isentos; terrenos e infra-estrutura subsidiados ou de preço nulo etc.

$O$ exame dessas políticas constitui requisito fundamental para se conhecer a efetiva capacidade de atração municipal, seus efeitos sobre as dinâmicas urbanas do município e regióes adjacentes e, principalmente, o balanço crítico dos custos e benefícios efetivos, gerados pelos novos investimentos incentivados.

-Este texto tem como base relatório de pesquisa feito pelo autor em convênio com a Fundap/Unicamp/Depe ("Proposta metodológica sobre o desenvolvimento da economia paulista e a problemática de sua urbanização. Documento-base. Campinas, Unicamp, março de 1983, mimeogr.

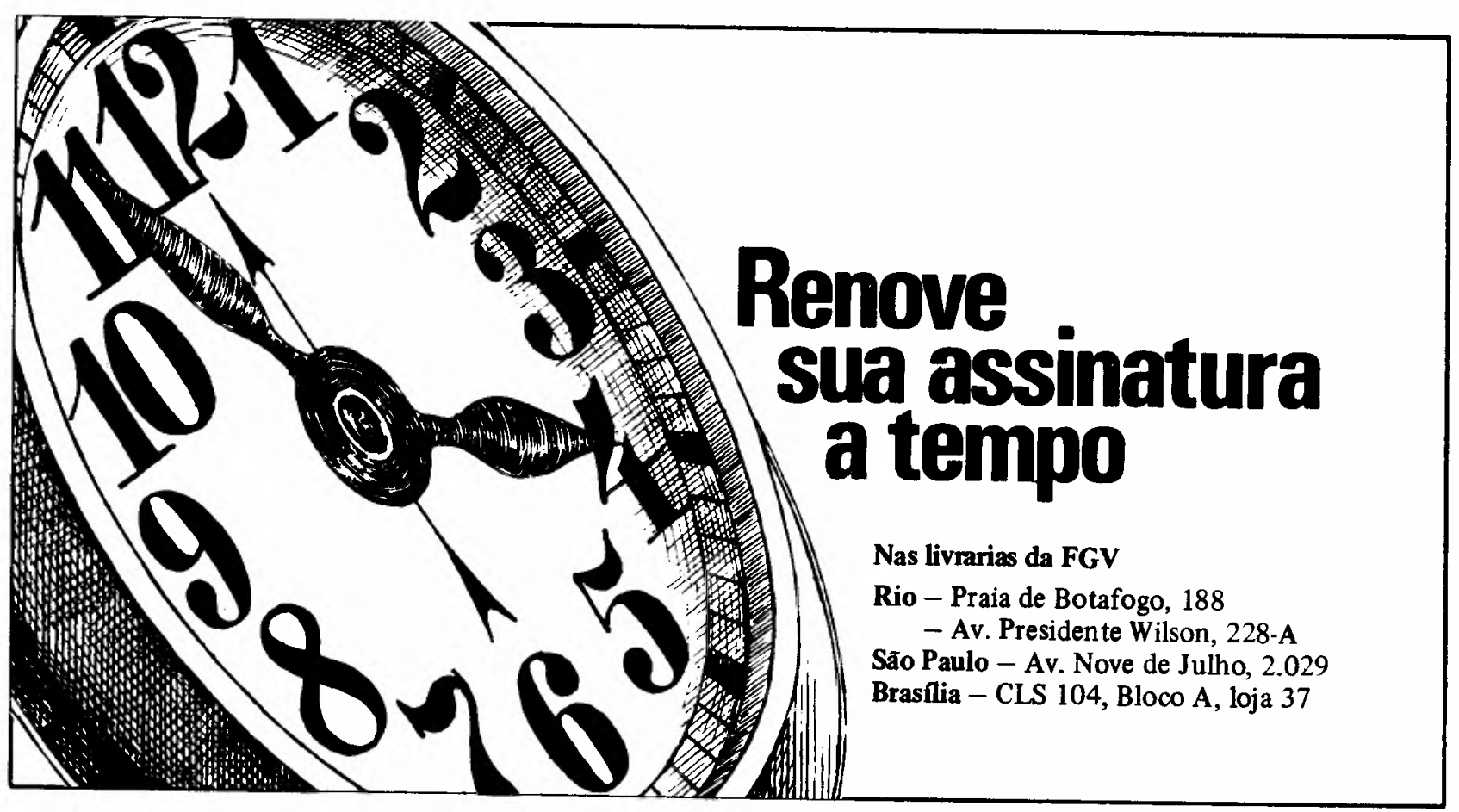

